\title{
Evidence of unusually explosive hydromagmatic eruptions and their role in the emplacement of the North Atlantic Igneous Province
}

\author{
ELLA WULFSBERG STOKKE ${ }^{1}$, EMMA J. LIU ${ }^{2}$, JACK \\ LONGMAN $^{3}$, DOUGAL A JERRAM ${ }^{1,4}$, JOHN M. \\ MILLETT $^{5,6}$ AND MORGAN JONES ${ }^{1}$ \\ ${ }^{1}$ University of Oslo \\ ${ }^{2}$ University College London \\ ${ }^{3}$ University of Oldenburg \\ ${ }^{4}$ DougalEARTH Ltd. \\ ${ }^{5}$ VBPR AS \\ ${ }^{6}$ University of Aberdeen \\ Presenting Author: e.w.stokke@geo.uio.no
}

The North Atlantic Igneous Province (NAIP) comprises extrusive and intrusive rocks along the east and west coast of Greenland, on plateaus and ridges in the North Atlantic, and in the Faroes and British Isles. The province was emplaced 63-52 Ma during the early stages of the opening of the Northeast Atlantic Ocean. The most voluminous activity was focused between $\sim 56$ and $54 \mathrm{Ma}$, leading to the emplacement of the bulk of the flood basalts and to the widespread deposition of volcanic ash layers. The Danish ash series is a succession of more than 180 of these layers outcropping in northwest Denmark, deposited during a 1.3 Myr period from about 55.9 Ma to 54.6 Ma. While some of the earliest ashes are heavily altered and a mix of magma compositions, most of the later ashes are composed of almost pristine tholeiitic basalts.

The thicknesses of the ash layers and the long distances from potential source volcanoes suggest unusually large and explosive eruptions, likely due to explosive magma-water interactions. Still, quantitative or qualitative investigation into the style and extent of possible hydromagmatic volcanism for the NAIP ashes are lacking. Hydromagmatic activity is governed by a complex interplay of several factors, such as the relative amounts of magma and water, the depth of subaqueous eruptions, and the magma composition. We measured the residual sulfur concentrations in pristine matrix glasses and the variation in ash morphology and vesicularity through the ash stratigraphy. Together, these data allow us to model the changes in volatile degassing and evaluate the degree of magma-water interaction during the fragmentation process. Our results suggests that the Danish ash series is indeed a result of hydromagmatic activity, likely triggered by the opening of the Northeast Atlantic Ocean.

The ashes are sourced from the NAIP somewhere within the opening rift, yet the precise source is still poorly constrained. Recent improvements in our knowledge of NAIP geochemical compositions enables a more detailed comparative study with the Danish ashes. We therefore also present an updated regional correlation which improves our understanding of the evolution of the explosive component of NAIP activity. 